特集 脳動脈瘤治療の部位別検討課題

原 著

\title{
内澒動脈前脈絡叢動脈分岐部動脈瘤の臨床的特徴と手術成績
}

\author{
河本 俊介, 深谷 春介, 安部 欣博 \\ 奥貫かなえ，金谷 英明，金虎
}

\section{Anterior Choroidal Artery Aneurysms: Clinical Characteristics and Surgical Outcome}

Shunsuke Kawamoto, M.D., Shunsuke Fukaya, M.D., Yoshihiro Abe, M.D., Kanae Okunuki, M.D., Hideaki KanaYa, M.D., and Phyo KIM, M.D.

Department of Neurosurgery, Dokkyo Medical University, Tochigi, Japan

\begin{abstract}
Summary: Surgical treatment of anterior choroidal artery (AChA) aneurysms used to be associated with a high risk of ischemic stroke in the AChA territory. We retrospectively studied 70 consecutive patients with AChA aneurysms to evaluate their clinical characteristics and surgical outcome against the background of routine use of indocyanine green video angiography and motor-evoked potential (MEP). Between 2007 and 2016, 70 procedures were performed for 70 patients with AChA aneurysms. AChA aneurysms were the primary target in 45 patients and the secondary target in 25 patients. Nineteen patients were men and 51 were women, with a mean age of 60.1 years. The mean size of the aneurysm was $4.2 \mathrm{~mm}$. Sixty-eight aneurysms were obliterated with clips. Combination of multiple clips was required in 18 aneurysms to secure the patency of the origin of AChA. Decreased MEP amplitude was observed in 8 of 68 procedures with MEP monitoring but fully recovered after readjustment of the clips. None of the 49 patients without subarachnoid hemorrhage (SAH) and 12 patients with SAH grades 1 and 2 according to the World Federation of Neurological Surgeons classification developed symptomatic ischemia of AChA. Postoperative diffusion-weighted imaging revealed high intensity in the AChA territory in one patient, but the lesion was asymptomatic. Provided that sufficient operative field is obtained to allow inspection of the aneurysm in multiple angles and careful angioplastic clipping technique is utilized under appropriate monitoring, surgical clipping of the AChA aneurysm is associated with low risk of ischemic complications.
\end{abstract}

\author{
Key words: \\ $\cdot$ anterior choroidal artery \\ - cerebral aneurysm \\ - clipping \\ - ischemic complication
}

Surg Cereb Stroke

(Jpn) 45: 177-182, 2017

\section{はじめに}

内頝動脈 (internal carotid artery：IC)-前脈絡叢動脈 (anterior choroidal artery：AChA) 分岐部動脈瘤(以下, AChA 動脈瘤) は, 隣接する AChA の血流障害に伴う重篤 な神経脱落症 状 ${ }^{1)}$ を合併しやすいことから, 直達術のリス

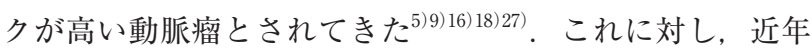
では運動誘発電位 (motor evoked potential：MEP)をはじ めとした電気生理学的モニタリング ${ }^{23)}$ およびインドシアニ ングリーン (ICG) を用いた術中蛍光血管造影 ${ }^{20)}$ (以下, ICG 蛍光血管造影) などを用いた real-time での安全確認を行う ことにより，虚血性合併症を確実に回避できたとする報告 
Table 1 Clinical characteristics of the 70 patients with AChA aneurysms

\begin{tabular}{|c|c|c|c|c|}
\hline & \multicolumn{2}{|c|}{ Primary } & \multirow{2}{*}{ Secondary } & \multirow{2}{*}{ Total } \\
\hline & Ruptured & Unruptured & & \\
\hline Number & 13 & 32 & $25^{*}$ & 70 \\
\hline Sex (M:F) & $5: 8$ & $12: 20$ & $2: 23$ & $19: 51$ \\
\hline Age [y] (range) & $58.2 \pm 15.8(28-76)$ & $61.0 \pm 11.4(28-74)$ & $60.0 \pm 11.2(36-77)$ & $60.1 \pm 12.2(28-77)$ \\
\hline Size of aneurysm [mm] (range) & $4.8 \pm 1.3(2.7-10.4)$ & $5.0 \pm 1.6(3-9)$ & $3.0 \pm 0.7(2-4)$ & $4.2 \pm 1.6(2-10.4)$ \\
\hline Single:multiple & $12: 1$ & $28: 4$ & $(0: 25)$ & $40: 30$ \\
\hline WFNS 1/2/4/5 & $3 / 4 / 5 / 1$ & - & $4 / 1 / 3 / 0$ & $7 / 5 / 8 / 1$ \\
\hline
\end{tabular}

AChA: anterior choroidal artery, WFNS: World Federation of Neurological Surgeons

*Eight and 17 cases were secondary to ruptured and unruptured aneurysms of other locations, respectively

が複数みられるようになった213)19)25).

われわれの施設では 2007 年以降, ICG 蛍光血管造影に 加え MEP も，破裂急性期の臨時手術でも必要に応じて施 行可能な体制をとっている。この体制の下で行った AchA 動脈瘤の直達手術の成績, ならびにその臨床的特徴と手術 における注意点について報告する.

\section{対象・方法}

2007 年 2 月から 2016 年 9 月の期間に当施設において直 達術を行った AChA 動脈瘤の 70 例を対象とした。 AChA 動脈瘤が手術の primary targetであったものが 45 例(破 裂 13 ，未破裂 32$)$ ，他部位の primary aneurysm の手術時 に付随的に操作を行ったものが 25 例(うち primary aneurysm が破裂動脈瘤であったものが 8 例)であった．同期 間に直達術を行った全動脈瘤は 1,129 個(破裂 422 , 未破裂 707），このうち内頝動脈の動脈瘤は 391 個（破裂 144, 未 破裂 247) であり，AChA 動脈瘤は全動脈瘤の $6.2 \%$ (内頚 動脈瘤の $17.9 \%$ ），破裂動脈瘤の $3.1 \%$ (破裂内頝動脈瘤の $9.0 \%$ )，未破裂動脈瘤の $8.1 \%$ (未破裂内澒動脈瘤の $23.1 \%$ ) を占めた。男性 19 例，女性 51 例，平均年齢は 60.1 歳 (2278 歳), 動脈瘤の大きさは, 破裂瘤が $4.8 \mathrm{~mm}(2.7-10.4$ $\mathrm{mm})$, primaryの未破裂瘤が5.1 mm(3.0-9.0 mm), secondary の瘤では $3.0 \mathrm{~mm}(2.0-4.0 \mathrm{~mm})$ であった。多発動脈 瘤は 30 例 $(42.9 \%)$ にられ，そのうち破裂瘤では $1 / 13$ $(7.7 \%)$, primary の未破裂瘤では 4/32(12.5\%)であった (Table 1)。多発動脈瘤として合併した瘤の部位は, posterior communicating artery $(\mathrm{PCoA}) 16$, middle cerebral artery (MCA) 7, anterior communicating artery (ACoA) /internal carotid artery bifurcation(ICB)/ophthalmic artery (OphA) 各 3, basilar artery (BA)-superior cerebellar artery (SCA) 1 の計 33 個であった。症候性の AChA 動脈 瘤は, 破裂瘤の 13 例と, 同側の動眼神経麻痺で発症した 切迫破裂の未破裂瘤 1 例の計 14 例 (20.0\%)であった. secondary の瘤 25 個のうち, 術前から診断されていたものが
19, 他部位の primary aneurysm の術中にはじめて発見さ れたものが 6 〔うち subarachnoid hemorrhage (SAH)2] であった。

手術は通常の pterional approach で行った. 前頭葉を挙 上して内頝動脈分岐部上方からの視野を確保するのに加 え, 静脈を側頭葉からも徹底的に分離し, 動眼神経・テン 卜縁近傍のくも膜を切開して側頭葉内側部を後外方に圧排 し側方からの視野も十分に確保して, 可能なあらゆる方向 から AChA が確認できるようにした. 全例で ICG 蛍光血 管造影にて AChAの血流を確認した. MEP は未破裂の全 例のみならず破裂急性期例でも必要に応じて行ってお り，他部位の破裂瘤の術中にはじめて発見された 2 例を除 く68 例で施行した.

術中所見における AChA と動脈瘤の位置関係は, Group 1：AChA 起始部が neck から内頝動脈寄りで通常 のクリッピングで AChA を温存できるもの, Group 2: 起 始部が neck だが dome 寄りで AChA の温存に工夫または 注意を要するもの, Group 3: 起始部が動脈瘤の dome, と分類した (Fig. 1).

術後の画像評価としては, 非 SAH 例 $(\mathrm{n}=49)$ は術後 4 または 5 日目に, $\mathrm{SAH}$ 例 $(\mathrm{n}=21)$ は発症後 14-17 日目にそ れぞれ MRIを行い, 拡散強調画像にて急性期虚血巣の有 無を確認した。術後の日常生活機能については, 非 SAH 例では退院時(術後 8 日目), SAH 例では発症 3 力月後の 時点での modified Rankin Scale (mRS) を用いて評価を 行った.

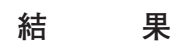

術中所見での AChA 起始部の分類は, Group 1/2/3 が それぞれ 39/19/12 例であった(Table 2).

動脈瘤䅡部のクリップによる閉塞は 68 例で行った。未 破裂の症例のうち, ネックを含めた瘤のほとんどが動脈硬 化性の硬い壁であった 1 例は, primary の動脈瘤であった が wrappingを選択した。また, secondaryの動脈瘤の 1 

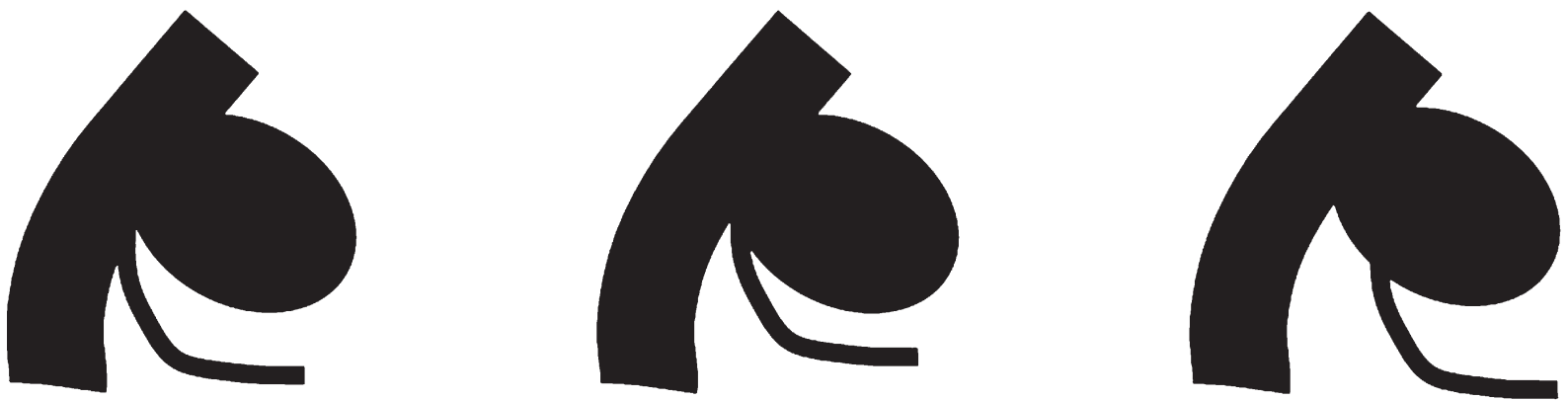

Fig. 1 Classification of IC-AChA aneurysms

A $\mid$ B $\mid$ C $\quad$ A: Group 1: AChA originating at the neck or deflecting toward the internal carotid artery.

B: Group 2: AChA originating at the neck but deflecting toward the aneurysm.

C: Group 3: AChA originating on the wall of the aneurysm.

Table 2 Classificaion of AChA aneurysms and operative results (number of clips used and change in MEP)

\begin{tabular}{|c|c|c|c|c|c|c|c|c|c|}
\hline & & \multicolumn{2}{|c|}{ Group 1} & \multicolumn{2}{|c|}{ Group 2} & \multicolumn{2}{|c|}{ Group 3} & \multicolumn{2}{|c|}{ Total } \\
\hline & & Primary & Secondary & Primary & Secondary & Primary & Secondary & Primary & Secondary \\
\hline \multirow[t]{5}{*}{ Number of clips } & 0 & 0 & 0 & 1 & 0 & 0 & 1 & 1 & 1 \\
\hline & 1 & 20 & 17 & 5 & 3 & 2 & 2 & 27 & 22 \\
\hline & 2 & 1 & 1 & 9 & 1 & 6 & 0 & 16 & 2 \\
\hline & 3 & 0 & 0 & 0 & 0 & 1 & 0 & 1 & 0 \\
\hline & Subtotal & 21 & 18 & 15 & 4 & 9 & 3 & 45 & 25 \\
\hline \multicolumn{2}{|l|}{ Total } & \multicolumn{2}{|c|}{39} & \multicolumn{2}{|c|}{19} & \multicolumn{2}{|c|}{12} & \multicolumn{2}{|r|}{70} \\
\hline \multicolumn{2}{|c|}{ MEP decreased*/monitored } & \multicolumn{2}{|c|}{$1 / 37$} & \multicolumn{2}{|c|}{$5 / 19$} & \multicolumn{2}{|c|}{$2 / 12$} & \multicolumn{2}{|c|}{$8 / 68$} \\
\hline
\end{tabular}

AChA: anterior choroidal artery, MEP: motor evoked potential

*MEP recovered after re-adjustment of the clip

A $\mid \mathbf{B}$

Fig. 2 Combination clipping for group 2/3 aneurysms

A: The AChA originates at the neck (arrow), and the origin is deflected to the aneurysm (Group 2).

B: The first clip is applied to the dome of the aneurysm, with a small space left around the neck. The second clip, which is shorter, is applied at the residual space at the neck, parallel to the tip of the blade and a few millimeters apart from the origin of the AChA.
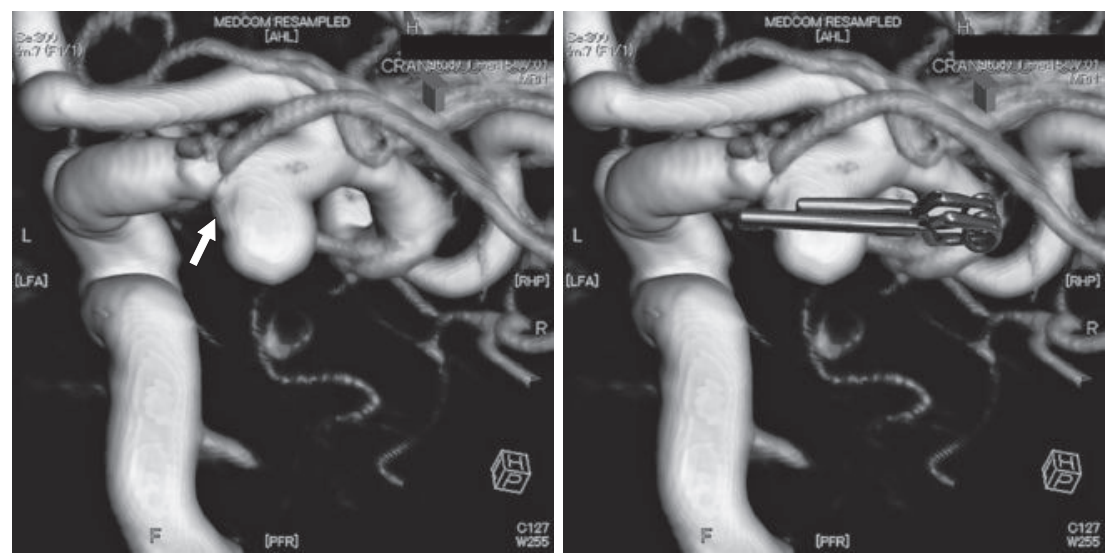

例では，動脈瘤がきわめて小さくかつ Group 3 であった ためwrapping を選択した.

クリッピングに際し複数のクリップを用いて AChA 流 出路の形成を行ったものは, Group 2 で 10 例, Group 3 で 7 例であった(Table 2). Group 2 の瘤に対して 2 本の クリップで流出路の形成を行う際のイメージ図を Fig. 2 に示した. Group 1 で 2 個のクリップを使用した例は, 径 $9 \mathrm{~mm}$ の瘤に対して補強目的で 1 本のクリップを追加した
ものであった.

術中の MEP 変化は 8 例 $(11.8 \%)$ でみられ，このうち Group 2 と Group 3 ではそれぞれ $26.3 \% ， 16.7 \%$ と高率に みられた。これらの変化はすべてクリップの修正により回 復した. ICG 蛍光血管造影にて視覚的に AChA の血流低 下を認めたものは 1 例で，この例では同時に MEP 変化も認 めた，その症例を Fig. 3 に示す，長径 $8 \mathrm{~mm}$ の左 AChA 動 脈瘤で, digital subtraction angiography (DSA)にて AChA 


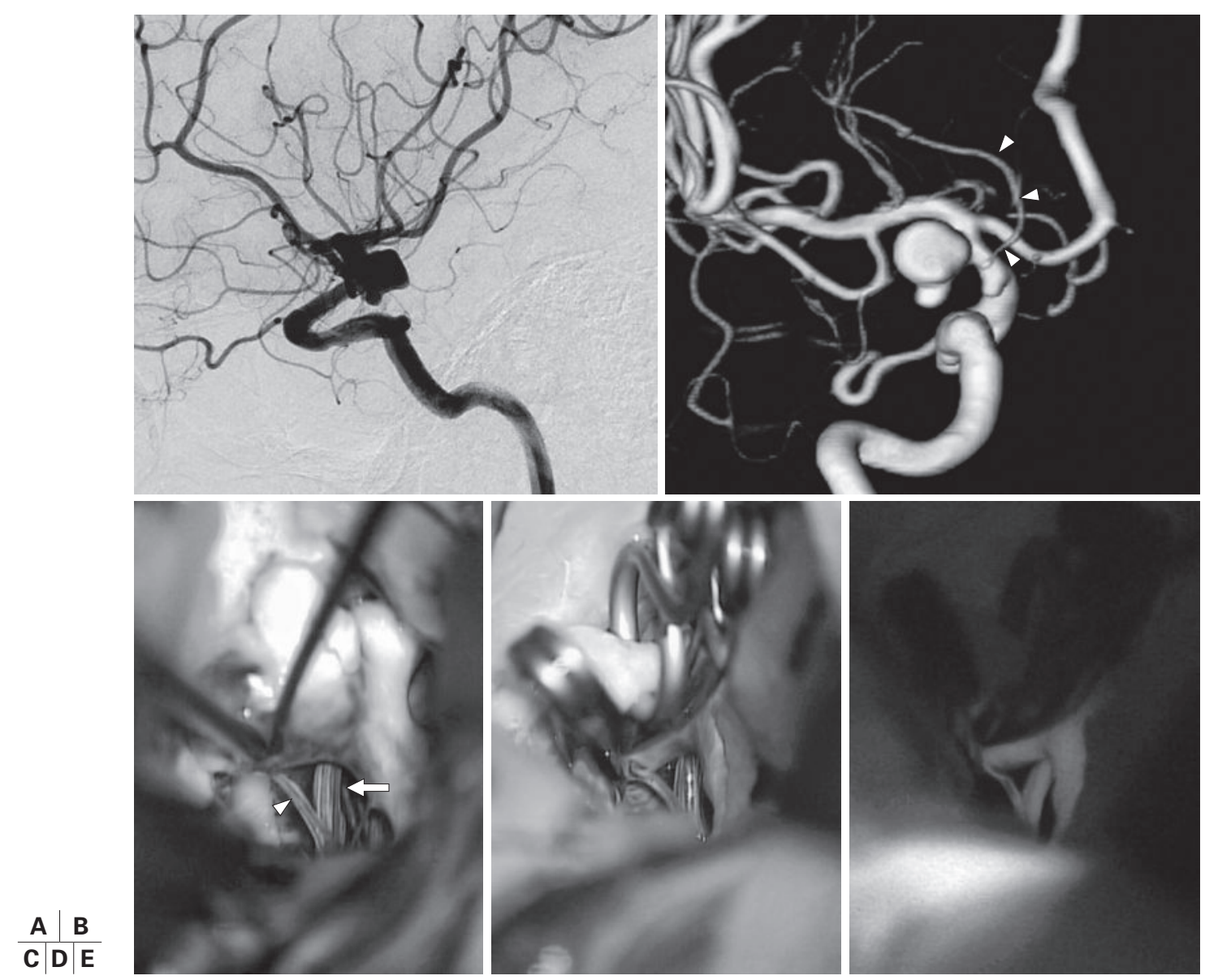

Fig. 3 Group 3 aneurysm

A: A left carotid angiogram showing an anterior choroidal artery aneurysm.

B: A posterior view of the three-dimensional image of the left carotid angiogram demonstrating a single trunk of the anterior choroidal artery (arrowheads).

C-E: Intraoperative photographs. The main trunk of the anterior choroidal artery (arrow) is free from the aneurysm, but another small branch is arising from the wall of the aneurysm (arrowhead) (C). Involvement of this branch resulted in disappearance of motor-evoked potential (MEP), and three clips were used to reconstruct the outflow of the vessel (D). The indocyanine green video angiogram confirms the patency of the vessel $(\mathbf{E})$, and the MEP fully recovered.

本幹ははっきりと描出されていたが(Fig. 3A, B), 術中所 見ではこのほかに非常に細い AChA が動脈瘤の側壁から 分岐していた(Fig. 3C)。この血管が kinkし ICG での描出 が不良になると MEPの消失を認めたため, combination clip にてこの血流を温存した(Fig. 3D，E)。なお，ICGの 所見のみでクリップ修正を行った例はなかった.

術後, AChAの虚血症状を呈したものはなかった。術 後の MRIにて Group 1 の非 SAH 例 1 例で拡散強調画像 上 AChA 領域の一部に高信号域の出現を認めたが $($ Table 3), 視野を含め神経学的異常所見は出現せず，6力月後の MRI ではT2 強調画像および FLAIR のいずれにおいても 慢性期の虚血巣を認めなかった。なお，この例では術中の MEP 変化は認めなかった。
非 SAH 例 $(\mathrm{n}=49)$ の退院時, および $\mathrm{SAH}$ 例のうち WFNS grade 1 または 2 の軽症例 $(n=12)$ の発症後 3 カ月 の時点での $\mathrm{mRS}$ は全例で 0 であり, AChAの虚血による 神経学的後遺症の発生は認めなかった (Table 3).

\section{考察}

AChA 動脈瘤は全脳動脈瘤の 2-5.5\%とされ それ自体の頻度はさほど高くはないが, 多発脳動脈瘤の一 つとしてみられることが $25-61 \%$ と多く(15)26)27)，他部位の 動脈瘤の処理を行う際に付随的に AChA 動脈瘤を扱う機 会も含めれば，遭遇する機会は決してまれとはいえない．

AChA 動脈瘤の手術において最も大きな問題になるの が AChA の虚血で，その症状は Abbie 症候群としてよく 
Table 3 Clinical and neuroradiological outcome of AChA aneurysms

\begin{tabular}{|c|c|c|c|c|c|c|c|c|c|}
\hline & & & \multicolumn{7}{|c|}{$\mathrm{mRS}$} \\
\hline & & & 0 & 1 & 2 & 3 & 4 & 5 & Total \\
\hline \multirow[t]{2}{*}{ No SAH $(n=49)$} & & & 49 & 0 & 0 & 0 & 0 & 0 & 49 \\
\hline & DWHI of $\mathrm{ACh}$ & & $1^{*}$ & 0 & 0 & 0 & 0 & 0 & 1 \\
\hline \multirow[t]{5}{*}{$\mathrm{SAH}(\mathrm{n}=21)$} & WFNS grade & 1 & 7 & 0 & 0 & 0 & 0 & 0 & 7 \\
\hline & & 2 & 5 & 0 & 0 & 0 & 0 & 0 & 5 \\
\hline & & 4 & 1 & 0 & 0 & 2 & 3 & 2 & 8 \\
\hline & & 5 & 0 & 0 & 0 & 1 & 0 & 0 & 1 \\
\hline & DWHI of $\mathrm{ACh}$ & & 0 & 0 & 0 & 0 & 0 & 0 & 0 \\
\hline \multirow[t]{2}{*}{ Total } & & & 62 & 0 & 0 & 3 & 3 & 2 & 70 \\
\hline & $\mathrm{DWHI}$ of $\mathrm{ACh}$ & & 1 & 0 & 0 & 0 & 0 & 0 & 1 \\
\hline
\end{tabular}

AChA: anterior choroidal artery, mRS: modified Rankin scale, SAH: subarachnoid hemorrhage, DWHI: diffusion-weighted high intensity, WFNS: World Federation of Neurological Surgeons

*Asymptomatic; MEP remained unchanged during the procedure

知られている ${ }^{1)}$.この虚血合併症の出現率は, 以前は $12.5^{-}$ $22.6 \%{ }^{315) 9(16) 1827)}$ とかなり高率であったが, ICG 蛍光血管造 影 $^{20)}$ や $\mathrm{MEP}^{23)}$ を含む電気生理学的モニタリングをルーチ ンに用いる環境が整うようになって以降，ほとんどみられ なくなった2)1319925).

今回の当施設での検討でも, ICG 蛍光血管造影と MEP モニタリングをルーチンに用いることにより, 評価可能な 例での症候性の虚血合併症の出現はなかったが，今回の当 施設での経験に過去の報告も加え, 虚血合併症の予防・回 避に重要と思われるいくつかの点につき検討する.

まず，AChA は起始部の variation が多いことを認識し ておく必要がある. AChA の起始部の位置の variation ${ }^{10) 12)}$ や duplication などの報告もあり ${ }^{4) 21)}$, 注意が必要である.

Fig. 3 に提示した例のように, 術前の画像で確認できる血 管がすべてとは限らず，実際の術野でしか確認できないよ うな, 本幹とは別の小血管のみの血流障害でも MEP の消 失をきたし得るのであり，このような小血管の存在の可能 性にも十分注意を払う必要がある。また, 動脈瘤と $\mathrm{ACh} A$ の位置関係もさまざまで27), 特に AChA が動脈瘤 壁から分岐している場合には虚血を合併する危険性が高い とされる(2)13325)。これらのことを考えると, Yasargil ら 27) が強調しているように, IC 分岐部 (上方), IC と側頭葉と の間 (側方)，および脚間槽(後方)のスペースを用いた徹底 的な直視観察と剝離操作が必須であり, そのためには十分 な広さの開頭とシルビウス裂の分離が必要である．かつて Drake $ら^{6)}$ は, AChA 動脈瘤は外側の projection であるの に対し AChA 本幹は内側にあるのでクリップを進めるう えで問題になることはないとし，また最近でも Lehecka $ら^{15)}$ は, ほとんどの AChA 動脈瘤ではシルビウス裂の近 位部 10-20 mm のみ分離すれば十分と述べているが, 確実 な虚血合併症予防の観点からすれば，より慎重かつ周到な
操作が求められる.

術中支援装置として, ICG 蛍光血管造影は現在ではほと んどの施設で用いられていると思われるが, 術中に AChAの patency 確認したにもかかわらず術後 AChA 領域の虚血をきたした例があることが報告されており 注意が必要である。また，術後の DSAにて AChA が良好 に描出されているにもかかわらず AChA の虚血をきたす 例があることが複数報告されてお拈 ${ }^{39916)}$ ，ドップラー血 流計を用いて血流確認を行ったにもかかわらず虚血を生じ た例の報告もみられる ${ }^{918)}$. これらの原因としては, DSA やドップラーでは Fig. 3 に提示したような, 本幹の存在 に隠れてしまうょうな小血管を見逃している可能性が考え られる. ICGによる確認においても同様に本幹以外の細い 血管の描出を十分に確認するよう注意する必要がある.

MEP のモニタリングは内包後脚を通る錐体路の虚血の 検出にきわめて有用であり ${ }^{23)}$ ，特に AChA 動脈瘤の手術 に打いては術後の片麻痺を予防するためにほぼ必須と考え られる.ICG と MEPを併用した施設において, ICGで AChA の patency を確認したにもかかわらず MEP の変化 を生じた例の存在が報告されており ${ }^{13)}$ ，現在一般に用いる ことのできる術中支援装置としては MEP が最も有用と考 えられる。しかしながら, 中大脳動脈瘤の手術におい て，MEPの変化を認めなかったにもかかわらず術後遅発 性の穿通枝梗塞を認めた例の存在も報告されており ${ }^{11)}$,

MEPも万能というわけではないことは認識しておかねば ならない。邆発性の虚血の原因の 1 つとして, clip rotation (clip torsion)が挙げられている ${ }^{9)}$. Sakuma ${ }^{22}$ は, ク リップ rotationに伴う AChA の狭窄が MEP の変化をき たし，クリップの修正により虚血を回避した例を報告して おり，このような可能性も考えて，閉頭の最後までモニ夕 リングを継続するなどの配慮が必要と思われる。 
AChAの血流温存のために工夫や方針の変更が必要に なる場合がある，動脈瘤のネックに動脈硬化や石灰化を認 める場合は虚血を合併する危険性が高いとされ ${ }^{24)}$, そのよ うな場合は十分に余裕をもたせてクリップをアプライした り，われわれの症例の 1 例で行ったように wrapping に変 更したりする判断が必要である。また, AChA と動脈瘤 の位置関倸がわれわれの Group 2 または Group 3 のよう な場合には，複数のクリップを組み合わせることで $\mathrm{ACh} A$ の流出路を形成する工夫が必要になるが, クリッ プの組み合わせのパターンについては Lawton ${ }^{14)}$ の著書が 非常に参考になる。このような手技に精通しておくと同時 に，術中所見に応じて最適の角度・深さでクリップをアプ ライすることができるように，十分な大きさの開頭および シルビウス裂の分離によって広い術野の展開を得ることが 不可欠である.

\section{結語}

AChA 動脈痕に対しては, (1)多方向からの徹底的な直 視的観察, (2) $\mathrm{AChA}$ 起始部の起始部形成, (3)各種の術中 支援装置の併用，に留意することにより，安全なクリッピ ング術が可能である.AChAの温存に関しては，本幹以 外の小血管の存在の可能性や, clip rotationによる遅発性 の虚血の発生の可能性などを念頭に置きつつ, 閉頭の最後 まで慎重に操作を完了することが肝要である.

\section{なお，本論文の主旨は第 45 回日本脳卒中の外科学会に} て報告した。

\section{文献}

1) Abbie AA: The blood supply of the lateral geniculate body, with a note on the morphology of the choroidal arteries. $J$ Anat 67: 491-521, 1933

2）青木孝親，野口 慶，小牧 哲，ほか：前脈絡叢動脈分岐部 動脈瘤に対するクリッピングの治療成績. 脳卒中の外科 43 : 442-447, 2015

3) Bohnstedt BN, Kemp WJ 3rd, Li Y, et al: Surgical treatment of 127 anterior choroidal artery aneurysms: a cohort study of resultant ischemic complications. Neurosurgery 73: 933-939, 2013

4) Carpenter MB, Noback CR, Moss ML: The anterior choroidal artery; its origins course, distribution, and variations. $A M A$ Arch Neurol Psychiatry 71: 714-722, 1954

5) Cho MS, Kim MS, Chang CH, et al: Analysis of Clip-induced Ischemic Complication of Anterior Choroidal Artery Aneurysms. J Korean Neurosurg Soc 43: 131-134, 2008

6) Drake CG, Vanderlinden RG, Amacher AL: Carotid-choroidal aneurysms. J Neurosurg 29: 32-36, 1968

7) Flamm ES: Aneurysms of Internal Carotid and Antterior Communicating Arteries. in Wilkins RH, Rengachary SS (eds): Neurosurgery. Vol 2. McGraw-Hill, New York, 1985, pp1394-1404

8) Flamm ES: Midcarotid Artery (Posterior Communicating and
Anterior Choroidal Artery) Aneurysms. in Apuzzo MLJ(ed): Brain Surgery. Vol 1. Churchill Livingstone, New York, 1993, pp958-970

9) Friedman JA, Pichelmann MA, Piepgras DG, et al: Ischemic complications of surgery for anterior choroidal artery aneurysms. J Neurosurg 94: 565-572, 2001

10) Fujii K, Lenkey C, Rhoton AL Jr: Microsurgical anatomy of the choroidal arteries: lateral and third ventricles. $J$ Neurosurg 52: 165-188, 1980

11) Irie T, Yoshitani K, Ohnishi $Y$, et al: The efficacy of motorevoked potentials on cerebral aneurysm surgery and newonset postoperative motor deficits. J Neurosurg Anesthesiol 22: 247-251, 2010

12）河本俊介, 持木かなえ, 金谷英明, ほか：内澒動脈後交通動 脈分岐部動脈瘤の pitfall 一後交通動脈から分岐する前脈絡叢 動脈. 脳卒中の外科 40: 409-413, 2012

13）兒玉裕司, 大西英之, 垰本勝司, ほか：内頚動脈-前脈絡叢 動脈分岐部動脈瘤の形態的特徴に基づく分類と手術. 脳卒中 の外科 39: 267-271, 2011

14) Lawton MT: Seven Aneurysms: Tenets and Techniques for Clilpping. New York, Stuttgart, Thieme, 2011

15) Lehecka M, Dashti R, Laakso A, et al: Microneurosurgical management of anterior choroid artery aneurysms. World Neurosurg 73: 486-499, 2010

16) Li J, Mukherjee R, Lan Z, et al: Microneurosurgical management of anterior choroidal artery aneurysms: a 16-year institutional experience of 102 patients. Neurol Res 34: 272-280, 2012

17) Locksley HB: Natural history of subarachnoid hemorrhage, intracranial aneurysms and arteriovenous malformations. Based on 6368 cases in the cooperative study. $J$ Neurosurg 25: 219-239, 1966

18）目黒俊成, 桑原 研, 冨田祐介, ほか：内頚動脈-前脈絡叢 動脈分岐部脳動脈瘤に対する治療一治療方法と虚血合併症に ついて. No Shinkei Geka 42: 917-923, 2014

19）太田貴裕, 水谷 徹 : 虚血性合併症を回避するための内頝動 脈前脈絡叢動脈分岐部動脈瘤のクリッピング手技. 脳卒中の 外科 41: 176-182, 2013

20) Raabe A, Nakaji P, Beck J, et al: Prospective evaluation of surgical microscope-integrated intraoperative near-infrared indocyanine green videoangiography during aneurysm surgery. J Neurosurg 103: 982-989, 2005

21) Rhoton AL Jr, Fujii K, Fradd B: Microsurgical anatomy of the anterior choroidal artery. Surg Neurol 12: 171-187, 1979

22) Sakuma J, Suzuki K, Sasaki T, et al: Monitoring and preventing blood flow insufficiency due to clip rotation after the treatment of internal carotid artery aneurysms. J Neurosurg 100: 960-962, 2004

23) Suzuki K, Kodama N, Sasaki T, et al: Intraoperative monitoring of blood flow insufficiency in the anterior choroidal artery during aneurysm surgery. J Neurosurg 98: 507-514, 2003

24) Szelenyi A, Beck J, Strametz R, et al: Is the surgical repair of unruptured atherosclerotic aneurysms at a higher risk of intraoperative ischemia? Clin Neurol Neurosurg 113: 129-135, 2011

25）宇田賢司, 石川達哉, 師井淳太, ほか：前脈絡叢動脈瘤のク リッピング術一当院での治療成績と問題点. 脳卒中の外科 41: 352-357, 2013

26) Yasargil MG: Anterior Choroidal Artery Aneurysms. in Yasargil MG(ed): Microneurosurgery. Vol 2. George Thieme, Stuttgart, 1984, pp99-108

27) Yasargil MG, Yonas H, Gasser JC: Anterior choroidal artery aneurysms: their anatomy and surgical significance. Surg Neurol 9: 129-138, 1978 